\title{
GEOPHYSICAL MEASUREMEN'TS AS EFFICIENT TOOLS FOR HYDROGEOLOGICAL INVESTIGATIONS
}

\author{
E. Castillo $^{+)}$, H. Figdor ${ }^{+)}$, K.-H. Roch ${ }^{+)}$, R. Spendlingwimmer ${ }^{++}$ \\ ${ }^{+)}$Technical University Vienna, Dept. of Geophysics, Vienna, Austria \\ ${ }^{+)}$BFPZ-Arsenal - Geotechnical Institute, Dept. of Hydrogeology and Applied Geophysics, \\ Vienna, Austria
}

\section{INTRODUCTION}

In a number of regions the endangering of groundwater reservoirs has been increased considerably by emerging of extensive residential areas in the neighbourhood of big cities or by means of accidents during the transport of dangerous goods. By this for water supply of a region hydrogeological investigations of water resources have become much more significant in recent years. Detailed knowledge of hydrogeological conditions is not only important for estimation of aquifer capacity but also an essential requirement for effective measures of protection and redevelopment.

In order to take these tasks into account, in most cases an extensive multidisciplinary investigation program is necessary. In those programs modern methods of geophysics play an essential part. Results of geophysical measurements offer $2 \mathrm{D}$ (3D) information about layering conditions in a more regional area and therefore criterions for specific selection of drilling locations and well positions.

\section{EXPLORATION REGION}

The object of this study is part of a sedimentary basin at the southern edge of crystalline rocks of the Bohemian massif in Austria. The Gallneukirchen's basin in the North of Linz in Upper Austria (Fig. 1) has been formed from a bay of the tertiary molasse sea. It's a subsidence basin along outside the region NW-SE striking of tectonic structures. The crystalline bedrock, which has become rugged by tectonic forces consists mainly of variscan granites. The tertiary sediments comprise fine clastic limnic-fluvial material, which is overlayed by coarse and fine clastic marine sediments.

Widespread sands ("Linzer" Sande), which are mostly covered by thick clayey-silty sediments ("Schlier") are of particulary interest as aquifer.

\section{TESTING PROGRAM}

For the whole region out of economic reasons only a few exploration drillings were planned. Beside logging and hydrodynamic measurements in boreholes, pumping tests, hydrochemical and isotope analysis therefor at the beginning of the investigations an extensive testing program with gravimetric, seismic and geoelectric measurements was intended (Fig. 2). First the essential task consisted of adapting measuring arrangements as good as possible to the various situations to get maximum information with a reasonable expenditure. So by suitable combination of different geophysical exploration methods the significance of the results can be considerably increased. 
The first topic concerned the structure of bedrock. For this purpose numerous gravity measurements were performed, mainly along roads crossing the basin (Fig. 2). For those measurements two gravity meters were used: a Lacoste Romberg Mod. G gravity meter and an automatically registrating Scintrex CG 3. Both instruments provided reproducable accuracy within a few $0.01 \mathrm{mgal}$. Scintrex CG 3 enabled to get data at each station within less than 3 minutes. By this way on about $21 \mathrm{~km} 735$ stations were measured. In order to get information about depth of bedrock refraction seismic measurements were done near the edge of the northern part of the basin.

In the center of the basin two reflection lines were measured. These lines were identical with profiles of gravity measurements. Results of reflection seismics should mainly give information about if it is possible to recognize structures within the sediment. Two GEOMETRICS ES 2401 (each 24 channels) were used for the measurements. As mechanical energy source a VAKIMPAK was available. Distance of geophones was $4 \mathrm{~m}(5 \mathrm{~m})$ and the sequence of source points was arranged in such way, that as maximum stack fold 48 (36) could be achieved.

Finally in order to enable differentiation between sandy and clayey layers Schlumberger soundings with $\mathrm{AB} / 2_{\mathrm{max}}=250 \mathrm{~m}$ were made.

\section{PROCESSING}

Gravimetric measurements: For density modelling following conditions were determining: - solid rock at the edge of the basin, - depths to bedrock, determined by refraction seismics in northern part of the basin, - some borehole-profiles on which the basement was reached. It tumed out, that a simple 2-layer density model sediment/bedrock first was sufficient to correspond to above mentioned conditions.

Seismics: Reflection seismic data processing was performed with PROMAX-2D software. The processing flow essentially comprised following steps: static corrections from refraction seismics, signal processing, velocity analysis, nmo-corrections, stacking, migration.

For evaluation of refraction seismics data and electrical soundings standard algorithms were used.

\section{RESULTS}

Composition of 2-layer density models have given a consistent 3D-model of the relief of bedrock. This model indicates a density contrast of about $-0.50 \mathrm{~g} / \mathrm{cm}^{3}$. The main structure is a trench parallel to outside the region NW-SE striking of tectonic structures and it descends to $\mathrm{SE}$ up to $170 \mathrm{~m}$ below surface. In the eastern part another trench possibly originated by faults appears. Here depths to bedrock come up to $200 \mathrm{~m}$ (Fig. 2).

Results of reflection lines B (Fig. 3) and C (Fig. 4) clearly indicate a change to alternate sandy and clayey layers. In the western part of these profiles a NW-SE striking structure can be seen in the sediment. Such situations can be recognized only by high resolution seismics. Change to bedrock especially on profile $C$ is vague. This is because of the fact that surface of bedrock is considerably decomposed. This also is indicated in a drilling profile nearby. A comparison with a 3-layer density model is given in Fig. 4.

Results of electrical soundings in this area indicate specific electric resistivities which are too low for searched sandy aquifers ("Linzer" Sand). So a criterion seems to be found, that allows to identify layers found by reflection seismics as aquifer. Significance of this method has yet to be confirmed by further electrical measurements. 


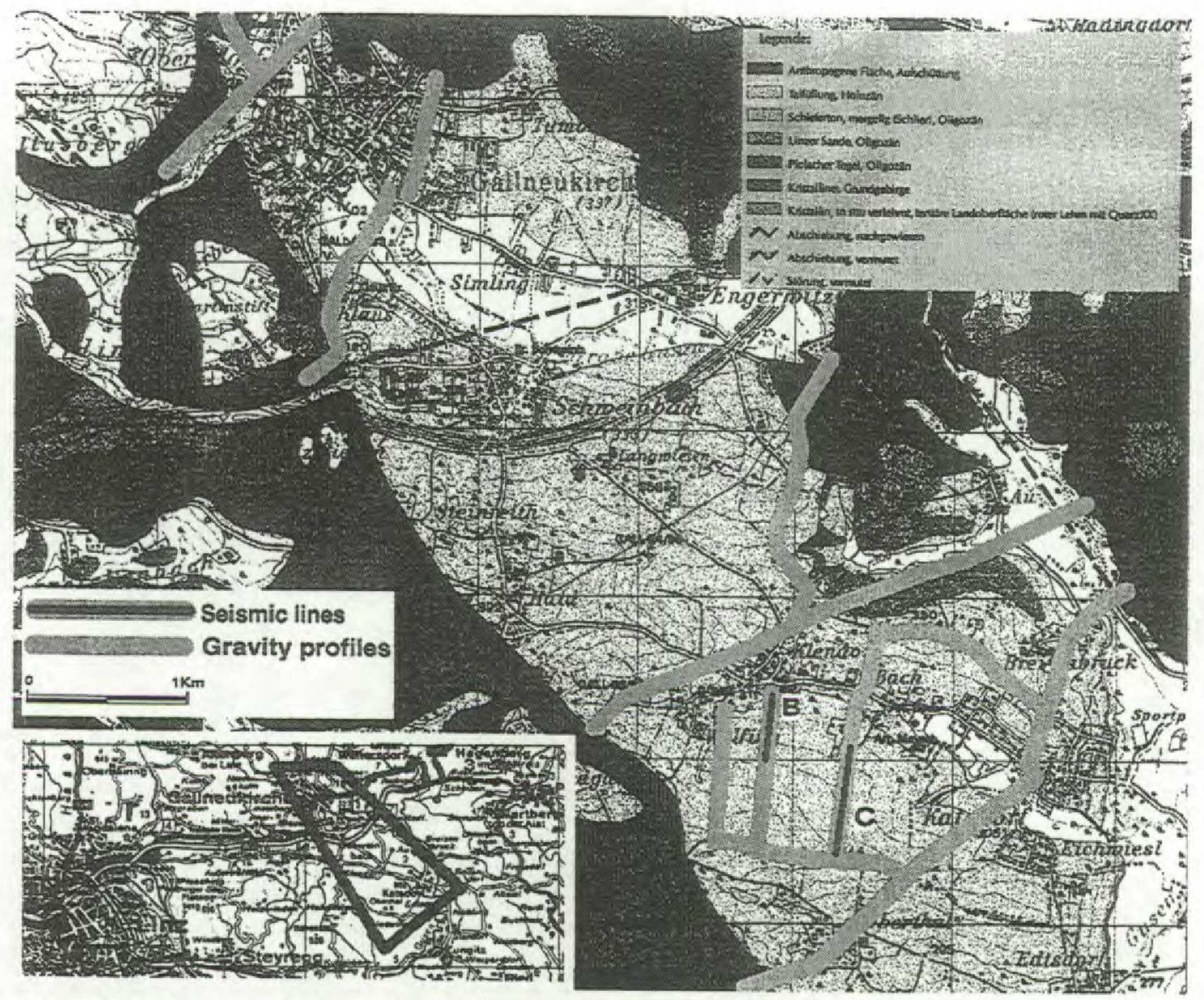

Fig. 1: Exploration region, geological situation, location of test sites



Fig. 2: Relief of exploration region with relief of the basement - geophysical profiles 


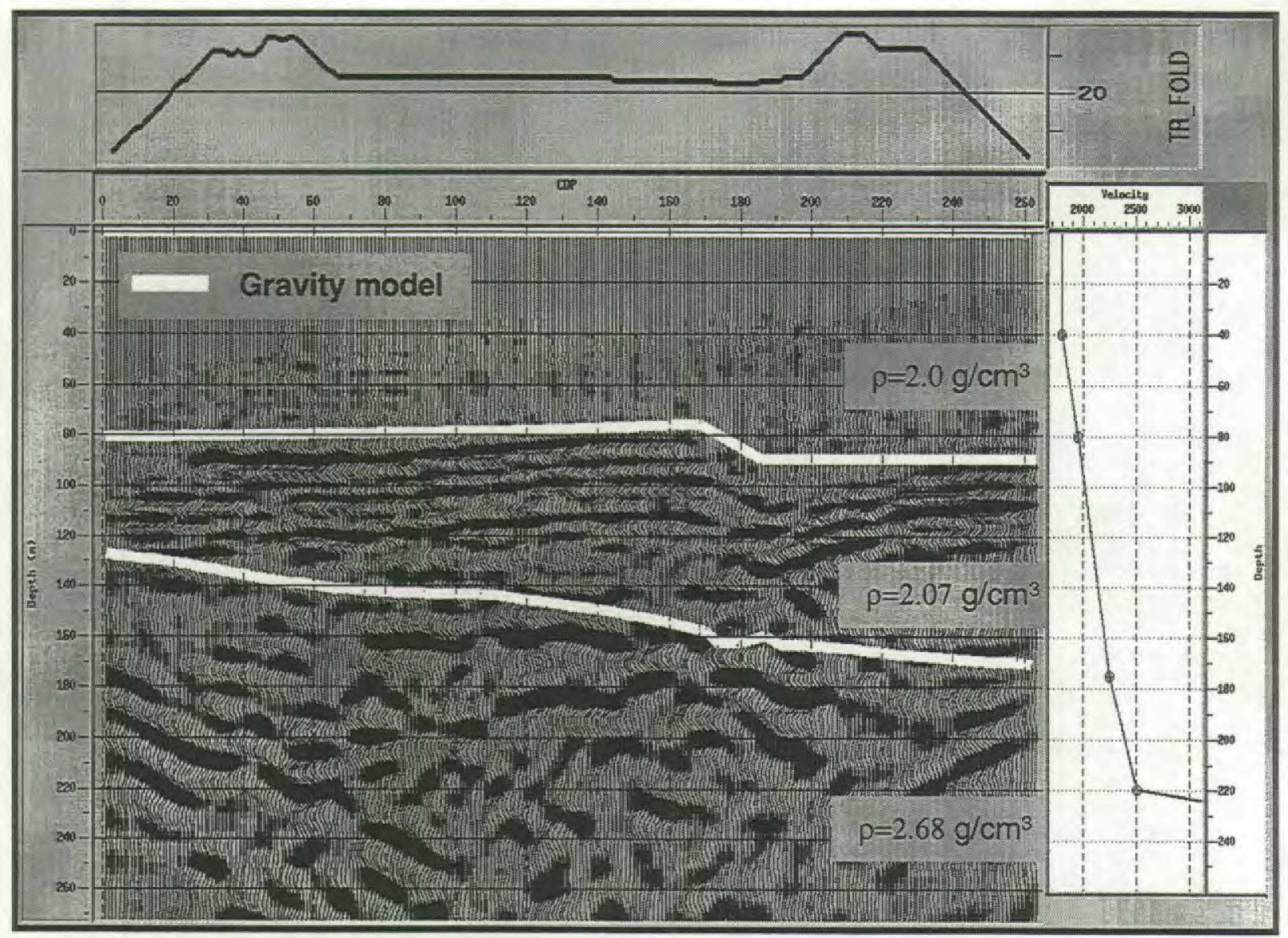

Fig. 3: Reflection line B - comparison with 3-layer density model



Fig. 4: Reflection line C - comparison with 3-layer density model 